\title{
Association of plasma insulin concentration to fatty acid distribution between milk fat and membrane synthesis
}

\author{
R. Mesilati-Stahy, ${ }^{*}$ H. Malka, $\dagger$ and N. Argov-Argaman ${ }^{* 1}$ \\ ${ }^{*}$ Animal Science Department, The Robert H. Smith Faculty of Agriculture, Food and Environment, The Hebrew University of Jerusalem, \\ Rehovot 76100, Israel \\ †Extension Service, Ministry of Agriculture, POB 28, Bet Dagan, Israel
}

\section{ABSTRACT}

We examined the association between plasma insulin concentration and fatty acid distribution to milk fat and membrane fractions (triglyceride and phospholipid, respectively) in dairy cows. Thirty-seven Holstein cows at 60 to $70 \mathrm{~d}$ postpartum were synchronized by $2 \mathrm{PGF}_{2 \alpha}$ injections $14 \mathrm{~d}$ apart. Plasma samples were taken before morning and evening milkings and milk samples were obtained at morning milking. Plasma insulin concentrations were determined and cows were retrospectively assigned to low insulin (LI; $2.8 \pm 0.2$ $\mathrm{ng} / \mathrm{mL}, \mathrm{n}=6$ ) or high insulin (HI; $5.9 \pm 0.6 \mathrm{ng} /$ $\mathrm{mL}, \mathrm{n}=7)$ experimental groups. Fatty acid analysis of milk samples demonstrated a possible association between plasma insulin concentration and the fatty acid composition in phospholipid and triglyceride fractions. In the HI group, monounsaturated fatty acid concentration tended to be higher in the triglyceride $(\mathrm{Tg})$ fraction than the phospholipids $(\mathrm{Pl})$ fraction. In the LI group, the concentrations of short- and mediumchain saturated fatty acids ( $<16$ carbon chain length), considered de novo-synthesized fatty acids, were higher in the triglyceride fraction than the phospholipid fraction. These results imply that the primary source of saturated fatty acids for phospholipid synthesis, in both HI and LI groups, is the circulation, as reflected by a higher concentration of longer saturated fatty acids (>16 carbon chain length) in the phospholipid fraction. Finally, the phospholipid-to-triglyceride ratio was higher in the HI group than in the LI group. Together, the results indicate that fatty acid distribution between phospholipid (membrane) and triglyceride (fat) synthesis by the mammary gland is associated with fatty acid length, degree of unsaturation, and origin, and might be subject to metabolic hormone regulation. Furthermore, a lower triglyceride-to-phospholipid ratio in the HI group implies that high plasma insulin and low milk

Received May 29, 2011.

Accepted December 13, 2011.

${ }^{1}$ Corresponding author: argov@agri.huji.ac.il fat concentrations are associated with a shift in the size distribution of milk fat globules.

Key words: milk fat, triglyceride, phospholipid, mammary gland

\section{INTRODUCTION}

From a human health perspective, consumption of a triglyceride ( $\mathbf{T g}$ )-rich diet is associated with obesity, atherogenesis, and type 2 diabetes (Lissner and Heitmann, 1995; WHO, 2000). On the other hand, diets rich in phosphoglycerides and sphingolipids have been shown to improve gut bacterial population (Newburg, 2009), intestinal cell functionality (Nilsson and Duan, 2006), and plasma lipid profile (Burgess et al., 2005; Pfeuffer and Schrezenmeir, 2007), and even prevent steatosis (Duivenvoorden et al., 2006). Milk fat consists of approximately $98 \% \mathrm{Tg}$ and $2 \%$ structural lipids, mainly phosphoglycerides and sphingolipids (i.e., phospholipids, Pl; Timmen and Patton, 1988). Therefore, identification of the mechanisms controlling FA partitioning between $\mathrm{Tg}$ and $\mathrm{Pl}$ by the mammary gland might enable the development of a novel approach to improve milk fat composition. Although many studies have identified factors regulating milk FA composition (Allred et al., 2006; Or-Rashid et al., 2009; BernalSantos et al., 2010), almost all of them have studied milk fat as a bulk product, overlooking its complex lipid composition.

Fatty acids in milk are principally esterified to glycerol to form Tg and phosphoglycerides, or esterified to sphingosine backbone to form sphingolipids (Jensen and Thompson, 1995). The variety of lipid species in milk is attributed to the unique secretion pathway of milk fat. Milk fat is secreted as a structure called the milk fat globule, which consists of a $\mathrm{Tg}$ core covered with 3 layers of $\mathrm{Pl}$ derived from the endoplasmic reticulum and the apical membrane of the epithelial cell. As part of the secretion process, the mammary gland epithelial cell envelops the emerging Tg droplet, thereby forming the milk fat globule membrane (Mather and Keenan, 1998). This membrane consists of complex structural lipids, including Pl, glycolipids, and cholesterol, derived 
Table 1. Ingredients and chemical composition of lactating cow diet

\begin{tabular}{lc}
\hline Nutrient analyzed & \% of DM \\
\hline Ingredients & \\
Ground corn grain & 25 \\
Ground barley grain & 2 \\
Rapeseed meal & 9 \\
Soybean meal & 12.1 \\
Sunflower meal & 1.5 \\
Wheat silage & 38.3 \\
Wheat & 4 \\
Wheat hay & 2 \\
Dried distillers grain & 4 \\
Salt & 1.4 \\
Calcium bicarbonate & 0.5 \\
Vitamins and minerals ${ }^{1}$ & 0.1 \\
Chemical composition & \\
NDF & \\
ADF & 30.2 \\
CP & 11.4 \\
Ether extracts & 18.1 \\
Net energy & (Mcal/kg of DM) \\
Ash & 4.3 \\
\hline
\end{tabular}

${ }^{1}$ Contained 20,000,000 IU of vitamin A/kg, 2,000,000 IU of vitamin $\mathrm{D} / \mathrm{kg}, 15,000 \mathrm{IU} / \mathrm{kg}$ of vitamin E, 6,000 IU $/ \mathrm{kg}$ of $\mathrm{Mn}, 6,000 \mathrm{mg} / \mathrm{kg}$ of $\mathrm{Zn}, 2,000 \mathrm{mg} / \mathrm{kg}$ of Fe, $1,500 \mathrm{mg} / \mathrm{kg}$ of $\mathrm{Cu}, 120 \mathrm{mg} / \mathrm{kg}$ of I, $50 \mathrm{mg} / \mathrm{kg}$ of Se, and $20 \mathrm{mg} / \mathrm{kg}$ of $\mathrm{Co}$.

${ }^{2} \mathrm{NDF}$ from forage and nonforage sources.

${ }^{3}$ Calculated using NRC (2001) guidelines.

from the apical membrane of the secreting epithelial cells.

Milk FA are considered to originate from 2 sources: FA with chain lengths of $<16$ carbons are considered to be the product of de novo synthesis within epithelial cells of the mammary gland, whereas FA with chain lengths of $>16$ carbons are considered to be derived from the circulation (Bauman and Griinari, 2003; Couvreur et al., 2007). Lactation stage, energy balance, plasma insulin concentration, and possibly reproductive state, are all factors found to modulate milk FA composition and milk fat concentration (Palmquist et al., 1969; Bachman et al., 1988; de Vries and Veerkamp, 2000). Negative energy balance and consequently decreased plasma insulin levels modify milk FA composition by elevating plasma NEFA availability for mammary gland utilization by inducing adipose lipolysis (Griinari et al., 1997; Bauman and Griinari, 2003; Corl et al., 2006). Hence, energy status and plasma insulin concentration influence the balance between absorbed and local, de novo-synthesized, FA utilization for milk lipid synthesis.

Whether the origin of FA alters their distribution between $\mathrm{Tg}$ and $\mathrm{Pl}$ synthesis by the mammary gland has never been studied. The purpose of this retrospective study was to examine the association of milk fat concentration, insulin, and FA distribution between $\mathrm{Tg}$ and $\mathrm{Pl}$ in milk.

\section{MATERIALS AND METHODS}

\section{Animals}

Milk and blood samples for this retrospective observational study were obtained from Holstein cows $(\mathrm{n}=$ 37) from the "Izrael" dairy herd, Israel, which were 60 to $70 \mathrm{~d}$ postpartum and in at least their second lactation. The health status of cows was monitored by the veterinarian starting 2 wk before the study began for a period of 5 wk. Only healthy cows were included in the study.

Cows were milked 3 times a day with an 8-h interval, and milk production was recorded electronically. In an effort to equalize the plasma concentration of steroid hormones (i.e., estradiol and progesterone) and to avoid confounders such as reproductive state, cows were synchronized with 2 injections of $\mathrm{PGF}_{2 \alpha} 14$ $\mathrm{d}$ apart. The cows were housed in the same lot and provided a TMR formulated to meet or exceed requirements (NRC, 2001) ad libitum (Table 1). Cows were visually scored for body condition on a 5-point scale in increments of 0.25 (Wildman et al., 1982) at dry off, parturition (between 5 and $12 \mathrm{~d}$ postpartum), and between 40 and $47 \mathrm{~d}$ postpartum.

\section{Samples and Insulin Measurements}

Samples were obtained $14 \mathrm{~d}$ after the first $\mathrm{PGF}_{2 \alpha}$ injection, ensuring that the majority of the cows were in the late luteal phase of their estrous cycle, with high progesterone plasma concentrations. The first blood sample was obtained $17 \mathrm{~h}$ after food had been distributed and $2 \mathrm{~h}$ before the morning milking. A second blood sample was taken after the evening milking, approximately $8 \mathrm{~h}$ after food distribution. Blood was collected from the coccygeal vessel into vacuum tubes (Becton Dickinson Systems, Crowley, UK). Plasma was immediately separated from the blood and stored at $-18^{\circ} \mathrm{C}$ until analysis. Milk was sampled during the morning milking, immediately after the first blood sample had been obtained, and stored at $-18^{\circ} \mathrm{C}$ until analysis. Milk yields were monitored and recorded by the "Afimilk" dairy herd management system (S.A.E. Afikim, Kibbutz Afikim, Israel). Milk fat and protein and lactose contents were determined by infrared analysis using a MilkoScan 4000 (Foss Electric, Hillerød, Denmark) at the Israeli Cattle Breeders Association (Caesarea, Israel).

Plasma insulin concentration in morning and evening samples was determined by RIA (Coat-A-Count Insulin diagnostic kit, Diagnostic Products Corp., Los Angeles, CA) with intra- and interassay CV of 7.2 and $5.1 \%$, respectively. 


\section{Experimental Design}

Plasma insulin concentration was determined in morning samples, and cows within the upper and lower quartiles of the insulin concentration scale were assigned to 2 groups accordingly: cows with morning insulin concentration of $>4.1 \mathrm{ng} / \mathrm{mL}$ (upper quartile) were selected for the high insulin (HI) group $(\mathrm{n}=7)$, whereas cows with insulin concentration of $<2.5 \mathrm{ng} /$ $\mathrm{mL}$ (lower quartile) were selected for the low insulin (LI) group $(\mathrm{n}=6)$. Fatty acid distribution between the different milk lipid fractions was evaluated for the retrospectively assigned groups.

\section{Extraction of Total Lipids}

Total milk lipids were extracted using cold extraction as described previously (Folch et al., 1957). Briefly, total lipids were extracted from $0.5 \mathrm{~mL}$ of milk with methanol:chloroform $(2: 1, \mathrm{vol} / \mathrm{vol})$. Then, $2 \mathrm{~mL}$ of double-distilled water was added, the upper phase was removed, and the solvent phase containing total lipids was filtered through a $0.45-\mu \mathrm{m}$ Teflon syringe filter (Axiva Sachem Biotech, New Delhi, India). Solvent was removed by evaporation under nitrogen flow to avoid oxidization, and $100 \mu \mathrm{L}$ of chloroform:ethanol (3\% vol:vol) was added. Total extracted lipids were stored at $-20^{\circ} \mathrm{C}$ for $\mathrm{GC}$ and HPLC analyses.

\section{Preparation of Fatty Acid Methyl Esters}

Fatty acid methyl esters were prepared from total milk fat and from the fractionated samples (i.e., $\mathrm{Tg}$ and $\mathrm{Pl}$ fractions) with $5 \%$ (vol/vol) methanolic $\mathrm{H}_{2} \mathrm{SO}_{4}$ at $65^{\circ} \mathrm{C}$ for $1 \mathrm{~h}$. Tubes were cooled before adding $1.9 \mathrm{~mL}$ of petroleum ether. After shaking, $3.5 \mathrm{~mL}$ of doubledistilled water was added. The upper layer was collected and evaporated under nitrogen flow, and $50 \mu \mathrm{L}$ of petroleum ether was added before injection for GC analysis.

\section{FA Classification}

To follow a fatty acid-utilization pathway and its association with their origin, FA have to be grouped according to chemical and physiological properties. Thus, we grouped the FA into SFA (C8:0, C10:0, C12:0, C13:0, C14:0, C15:0, C16:0, C17:0, C18:0, C20:0, C22:0, and C24:0), MUFA (C14:1, C15:1, C16:1, C18:1n-7, C18:1n-9, C18:1n-9 trans, C20:1, and C22:1), and PUFA (C18:2n-6, C18:3n-6, C18:3n-3, C20:4, C20:5, $\mathrm{C} 22: 4$, and $\mathrm{C} 22: 6)$. The SFA were further divided according to their assumed origin: de novo synthesis $(<16$ carbon chain length) or absorption from the circulation ( $>16$ carbon chain length).

\section{GC Analysis}

Chromatographic analysis was performed with a 6890N gas chromatograph (Agilent Technologies Wilmington, DE) equipped with a fused-silica (60 $\mathrm{m} \times$ $0.25 \mathrm{~mm}$ i.d., $0.25-\mu \mathrm{m}$ film) capillary column (DB-23, Agilent Technologies) under the following conditions: the oven temperature was programmed from $130^{\circ} \mathrm{C}$ to $170^{\circ} \mathrm{C}$ at a rate of $27^{\circ} \mathrm{C} / \mathrm{min}$, from $170^{\circ} \mathrm{C}$ to $215^{\circ} \mathrm{C}$ at a rate of $2^{\circ} \mathrm{C} / \mathrm{min}$, held at $215^{\circ} \mathrm{C}$ for $8 \mathrm{~min}$, from $215^{\circ} \mathrm{C}$ to $250^{\circ} \mathrm{C}$ at a rate of $40^{\circ} \mathrm{C} / \mathrm{min}$, and held at $250^{\circ} \mathrm{C}$ for $5 \mathrm{~min}$. Run time was $37.9 \mathrm{~min}$. Helium was used as a carrier gas at $2.21 \mathrm{~mL} / \mathrm{min}$. Flame-ionization detector temperature was $270^{\circ} \mathrm{C}$, and injector temperature was $280^{\circ} \mathrm{C}$. Air and hydrogen flows were adjusted to give maximal detector response. The split ratio was set at 1:100, and $1 \mu \mathrm{L}$ of sample was injected. Peak identification was based on relative retention times of 2 external standards. Fatty acid mole percentage was determined by calculating the molar ratio of each FA from the sum of moles of all identified FA in the sample. Fatty acids were recorded as percentage of total FA within each sample and within each lipid class (mol\%). Fatty acids for which more than $20 \%$ of the data were missing or below the limit of quantification were dropped from the analyses and considered undetermined in the results analysis.

\section{Separation of Polar and Neutral Lipids}

Quantification of $\mathrm{Pl}$ and determination of polar lipid class were performed by HPLC (HP 1200, Agilent Technologies) combined with a variable wavelength detector at $205 \mathrm{~nm}$ as described previously by Yandrasitz et al. (1981), using normal-phase chromatography on a silica column (Zorbax RX-SIL, $4.6 \times 250 \mathrm{~mm}$, Agilent Technologies). The detection was performed at $205 \mathrm{~nm}$ and the separation process was managed by ChemStation software (Agilent Technologies), with an injection volume of $20 \mu \mathrm{L}$. Separated neutral and polar lipid fractions were collected with a fraction collector (Teledyne Isco Inc., Lincoln, NE). The solvents were evaporated in a vacuum oven and the fractions prepared for GC analysis.

\section{Statistical Analysis}

All statistical procedures were performed using JMP software version 7 (SAS Institute Inc., Cary, NC). All reported data are means \pm standard errors $(\mathrm{SE})$ or 
Table 2. Milk and plasma parameters ${ }^{1}$ in cows with high (HI) and low (LI) plasma insulin concentrations

\begin{tabular}{lccc}
\hline Parameter & HI & LI & $P$-value \\
\hline Milk yield (kg/d) & $47.55 \pm 3.6$ & $42.6 \pm 1.3$ & 0.24 \\
Milk fat (\%) & $3.16 \pm 0.14$ & $3.67 \pm 0.14$ & 0.03 \\
Milk protein (\%) & $3.11 \pm 0.08$ & $3.02 \pm 0.07$ & 0.43 \\
ECM (kg/d) & $40.85 \pm 2.2$ & $39.56 \pm 2.4$ & 0.92 \\
FCM (kg/d) & $44.33 \pm 2.6$ & $43.71 \pm 2.8$ & 0.70 \\
Insulin morning (ng/mL) & $4.7 \pm 0.2$ & $1.4 \pm 0.2$ & $<0.0001$ \\
Insulin evening (ng/mL) & $7.08 \pm 0.76$ & $2.57 \pm 0.57$ & 0.03 \\
\hline
\end{tabular}

${ }^{1}$ Values are means $\pm \mathrm{SE} ; \mathrm{n}=7$ for the HI group and $\mathrm{n}=6$ for the LI group.

${ }^{2}$ Significance level of difference between LI and HI.

standard errors of the mean (SEM). Body condition scores were not determined for all cows at all 3 occasions and therefore data are presented as $\mathrm{LSM} \pm \mathrm{SE}$. Preliminary data analysis was performed for all milk samples in the study to evaluate their initial fat content. Differences between HI and LI groups were tested by Student $t$-test. Typically, for each variable, no more than one sample was considered an outlier. Correlation analysis was performed between dependent variables using the Multivariate and Correlation functions in JMP. Significance was set at $\alpha<0.05$. All dependent variables were checked for normality by the goodness of fit application of the JMP distribution analysis. If dependent variables were skewed, they were suitably transformed and analyzed accordingly.

\section{RESULTS}

\section{Plasma Insulin Concentration}

Plasma insulin concentration in the initial group of cows was $2.8 \pm 0.2$ and $5.9 \pm 0.6 \mathrm{ng} / \mathrm{mL}$ in the morning and evening samples, respectively (mean \pm SEM). At both samplings, plasma insulin concentration differed between the HI and LI groups (Table 2). Within each group, a high positive correlation was found between the morning and evening samples $\left(\mathrm{n}=14, \mathrm{R}^{2}=0.74\right.$, $P<0.003)$.

\section{Milk and Physiological Parameters}

Although selected according to their plasma insulin concentrations, the 2 groups also differed in their milk fat concentration: milk fat percentage was higher in LI cows than in HI cows (Table 2). Neither milk yield nor protein percentage differed between the HI and LI groups. Moreover, corrected values of milk energy and fat (ECM and FCM, respectively, for $3.5 \%$ fat) were similar. The differences between estimated BCS before dry off, at the beginning of lactation, and at peak lactation did not differ between the HI and LI groups (Table 3); however, BCS recorded at the beginning and at peak lactation were significantly higher in the HI cows.

\section{FA Composition of Total Milk Fat}

Endogenous plasma insulin concentration was associated with FA composition of the milk's total fat (Table 4). The HI group had reduced amounts (mol\%) of medium-chain fatty acids (C10:0, C12:0, and C14:0) and elevated stearic acid (C18:0). In addition, the relative concentration of arachidonic acid (C20:4n-6) was higher in milk from HI cows than from LI cows. Overall, milk from the LI cows was higher in SFA, and was made up of more short- and medium-chain fatty acids ( $<16$ carbon chain length), and less long-chain

Table 3. Body condition scores $^{1}$ of cows with high (HI) and low (LI) plasma insulin concentrations

\begin{tabular}{lrrc}
\hline Period & \multicolumn{1}{c}{ HI } & LI & $P_{\text {-value }}^{2}$ \\
\hline Dry off (A) & $3.7 \pm 0.2$ & $3.37 \pm 0.2$ & 0.38 \\
Start of lactation (B) & $3.5 \pm 0.1$ & $2.89 \pm 0.1$ & 0.01 \\
Lactation peak (C) & $3.17 \pm 0.1$ & $2.66 \pm 0.1$ & 0.02 \\
C - B $^{3}$ & $-0.5 \pm 0.1$ & $-0.16 \pm 0.1$ & 0.08 \\
C $-\mathrm{A}^{4}$ & $-0.41 \pm 0.1$ & $-0.66 \pm 0.1$ & 0.34 \\
$\mathrm{~A}-\mathrm{B}^{5}$ & $0.2 \pm 0.1$ & $0.5 \pm 0.2$ & 0.30 \\
\hline
\end{tabular}

${ }^{1}$ Values are LSM $\pm \mathrm{SE} ; \mathrm{n}=7$ for the HI group and $\mathrm{n}=6$ for the LI group.

${ }^{2}$ Significance level of difference between LI and HI.

${ }^{3}$ Change in BCS between lactation peak and start of lactation.

${ }^{4}$ Change in BCS between lactation peak and dry off.

${ }^{5}$ Change in BCS between dry off and start of lactation. 
Table 4. Fatty acid composition of whole milk $^{1}$ from cows with high (HI) and low (LI) plasma insulin concentrations

\begin{tabular}{lccc}
\hline FA $(\mathrm{mol} \mathrm{\%})$ & HI & LI & $P$-value $^{2}$ \\
\hline C8:0 & $0.037 \pm 0.007$ & $0.042 \pm 0.002$ & 0.87 \\
C10:0 & $0.11 \pm 0.05$ & $0.29 \pm 0.1$ & 0.06 \\
C12:0 & $2.28 \pm 0.24$ & $2.9 \pm 0.58$ & 0.01 \\
C14:0 & $13.11 \pm 0.45$ & $14.8 \pm 0.89$ & 0.01 \\
C16:0 & $41.6 \pm 0.6$ & $42.9 \pm 1.39$ & 0.69 \\
C16:1n-7 & $1.9 \pm 0.055$ & $2.3 \pm 0.09$ & 0.01 \\
C17:0 & $0.54 \pm 0.052$ & $0.49 \pm 0.02$ & 0.04 \\
C18:0 & $9.16 \pm 0.42$ & $22.6 \pm 0.32$ & 0.06 \\
C18:1n-9 & $25.3 \pm 0.8$ & $1.13 \pm 0.1$ & 0.05 \\
C18:1n-7 & $0.84 \pm 0.2$ & $3.66 \pm 0.2$ & 0.31 \\
C18:2n-6 & $4.11 \pm 0.13$ & $0.029 \pm 0.003$ & 0.05 \\
C18:3n-6 & $0.046 \pm 0.003$ & $0.25 \pm 0.03$ & 0.80 \\
C18:3n-3 & $0.29 \pm 0.03$ & $0.05 \pm 0.01$ & 0.06 \\
C20:0 & $0.02 \pm 0.006$ & $0.07 \pm 0.008$ & 0.16 \\
C20:1n-9 & $0.11 \pm 0.009$ & $0.16 \pm 0.02$ & 0.80 \\
C20:4n-6 & $0.19 \pm 0.019$ & $0.003 \pm 0.003$ & 0.03 \\
C20:5n-3 & $0.012 \pm 0.004$ & & 0.12 \\
\hline
\end{tabular}

${ }^{1}$ Values represent the mean mole percentage of each fatty acid from the mole sum of all identified fatty acids in the sample $(\mathrm{mol} \%) \pm \mathrm{SE} ; \mathrm{n}=7$ for the HI group and $\mathrm{n}=6$ for the LI group.

${ }^{2}$ Significance level of difference between LI and HI.

fatty acids ( $>16$ carbon chain length) relative to milk from HI cows.

\section{FA Composition in the Tg Milk Fraction}

Fatty acid composition in the $\mathrm{Tg}$ milk fraction from HI and LI cows was significantly different (Table 5). Most notable were the concentrations of the mediumchain fatty acids (C12:0 and C14:0), which were higher in milk from LI cows. Milk from the HI cows was enriched in MUFA in the cis, but not trans, conformation (C18:1). Both n-3 and n-6 fatty acids (C18:2n-6, $\mathrm{C} 18: 2 \mathrm{n}-3$, and $\mathrm{C} 20: 4 \mathrm{n}-6)$ were present at higher concentrations in the $\mathrm{Tg}$ fraction of milk from HI cows compared with that of LI cows.

\section{FA Composition in the PI Milk Fraction}

Fatty acid composition in the $\mathrm{Pl}$ milk fraction followed a trend opposite that of the $\mathrm{Tg}$ milk fraction (Table 6). Medium-chain fatty acid (C14:0) concentration was higher, whereas long-chain fatty acid (C18:0 and $\mathrm{C} 22: 1)$ concentrations were lower in $\mathrm{HI}$ compared with LI cows. Both n-6 and n-3 PUFA were typically equally distributed in the $\mathrm{Pl}$ fractions of the milk from HI and LI cows.

\section{Altered Partitioning of FA Classes into Tg and PI Milk Fractions}

Fatty acid class partitioning between $\mathrm{Tg}$ and $\mathrm{Pl}$ milk fractions was determined by calculating the relative concentration of each class in the $\mathrm{Tg}$ fraction minus its relative concentration in the $\mathrm{Pl}$ fraction (Figure 1). Figure 1 illustrates relative compositional changes between milk lipid fractions.

The SFA and PUFA classes were more equally distributed in the milk fractions from the HI group compared with the LI group. Milk from the HI group had relatively higher concentrations of short- and medium-chain saturated fatty acids in the $\mathrm{Pl}$ fraction than in the $\mathrm{Tg}$ fraction, as indicated by the negative value (Figure 1). In the LI group, a relatively higher concentration of short- and medium-chain saturated fatty acids was found in the $\mathrm{Tg}$ fraction compared with the $\mathrm{Pl}$ fraction. Relative higher concentrations of longchain saturated fatty acids ( $>16$ carbon chain length) were found in the $\mathrm{Pl}$ fraction compared with the $\mathrm{Tg}$ fraction in both groups of cows, although this pattern was more pronounced in the LI group than in the HI group. In the HI cows, relatively higher concentrations of MUFA were found in the $\mathrm{Tg}$ fraction than in the $\mathrm{Pl}$ fraction, as indicated by the positive value. The relative values also suggest that the LI group directed more MUFA to Pl synthesis than to Tg synthesis.

The relative concentration of polar $(\mathrm{Pl})$ to neutral (Tg) lipids in the milk was calculated (Figure 2), and HI cows had a higher $(P<0.05) \mathrm{Pl}$ :Tg ratio than the LI cows.

\section{DISCUSSION}

Plasma insulin concentration was monitored in cows in the lactation phase, which is characterized by a transition toward positive energy balance (Coffey et al., 2002). Milk was analyzed from cows in the lower and 
Table 5. Fatty acid composition of the fat (triglyceride) fraction in milk ${ }^{1}$ from cows with high (HI) and low (LI) plasma insulin concentrations

\begin{tabular}{|c|c|c|c|}
\hline $\mathrm{FA}(\mathrm{mol} \%)$ & HI & LI & $P$-value ${ }^{2}$ \\
\hline C6:0 & $0.7 \pm 0.14$ & $0.62 \pm 0.06$ & 0.54 \\
\hline $\mathrm{C} 8: 0$ & $0.102 \pm 0.01$ & $0.105 \pm 0.01$ & 0.51 \\
\hline C10:0 & $0.008 \pm 0.05$ & $0.093 \pm 0.03$ & 0.03 \\
\hline C12:0 & $0.4 \pm 0.2$ & $1.6 \pm 0.3$ & 0.02 \\
\hline $\mathrm{C} 13: 0$ & $0.08 \pm 0.04$ & $0.13 \pm 0.03$ & 0.24 \\
\hline C14:0 & $8.1 \pm 1.2$ & $10.93 \pm 1.4$ & 0.02 \\
\hline C14:1 & $0.5 \pm 0.14$ & $0.55 \pm 0.11$ & 0.23 \\
\hline C15:0 & $1.16 \pm 0.1$ & $1.47 \pm 0.04$ & 0.04 \\
\hline C15:1 & $0.22 \pm 0.04$ & $0.24 \pm 0.03$ & 0.84 \\
\hline C16:0 & $40.1 \pm 0.9$ & $41.9 \pm 1.6$ & 0.90 \\
\hline C16:1n-7 & $1.57 \pm 0.03$ & $1.74 \pm 0.2$ & 0.02 \\
\hline C17:0 & $0.62 \pm 0.06$ & $0.56 \pm 0.016$ & 0.01 \\
\hline C17:1 & $0.21 \pm 0.01$ & $0.18 \pm 0.01$ & 0.10 \\
\hline C18:0 & $11.2 \pm 0.6$ & $9.9 \pm 0.8$ & 0.03 \\
\hline C18:1n-9 trans & $2.7 \pm 0.2$ & $3.5 \pm 0.3$ & 0.48 \\
\hline C18:1n-9 cis & $25.3 \pm 0.6$ & $21.6 \pm 1.1$ & 0.02 \\
\hline C18:1n-7 & $1.2 \pm 0.04$ & $1.01 \pm 0.05$ & 0.47 \\
\hline C18:2n-6 & $3.9 \pm 0.07$ & $3.4 \pm 0.25$ & 0.02 \\
\hline C18:3n-6 & $0.04 \pm 0.01$ & $0.03 \pm 0.003$ & 0.21 \\
\hline C18:3n-3 & $0.27 \pm 0.006$ & $0.23 \pm 0.01$ & 0.02 \\
\hline C20:0 & $0.67 \pm 0.12$ & $0.55 \pm 0.09$ & 0.11 \\
\hline C20:1n-9 & $0.14 \pm 0.02$ & $0.11 \pm 0.03$ & 0.30 \\
\hline C20:4n-6 & $0.2 \pm 0.006$ & $0.15 \pm 0.01$ & 0.01 \\
\hline C20:5n-3 & $0.025 \pm 0.004$ & $0.017 \pm 0.006$ & 0.89 \\
\hline C22:0 & $0.02 \pm 0.004$ & $0.009 \pm 0.006$ & 0.53 \\
\hline $\mathrm{C} 22: 1$ & $0.066 \pm 0.016$ & $0.06 \pm 0.03$ & 0.55 \\
\hline $\mathrm{C} 22: 4 \mathrm{n}-6$ & $0.018 \pm 0.009$ & $0.007 \pm 0.007$ & 0.69 \\
\hline $\mathrm{C} 24: 0$ & $0.018 \pm 0.009$ & $0.006 \pm 0.006$ & 0.95 \\
\hline C22:6n-3 & $0.067 \pm 0.006$ & $0.047 \pm 0.012$ & 0.95 \\
\hline
\end{tabular}

${ }^{1}$ Values are means $\pm \mathrm{SE} ; \mathrm{n}=7$ for the HI group and $\mathrm{n}=6$ for the LI group.

${ }^{2}$ Significance level of difference between LI and HI.

upper quartiles of the insulin concentration scale. The high positive correlation between morning and evening plasma insulin concentrations within each group suggested a sustainable difference between the HI and LI groups. The 2 groups differed in their BCS at the beginning of lactation and at peak lactation, which might have contributed to the differences in plasma insulin and milk fat concentrations. Also, although not significant, BCS declined from the beginning to the peak of lactation in the HI group, whereas BCS of the LI group was constant. This may indicate that energy status and other (noninsulin) metabolic pathways contributed to the differences in milk lipid composition between the groups.

Evidence can be found in the literature for individual variation in the plasma insulin concentration in dairy cows, which is not the outcome of very negative energy balance (Gong et al., 2002; Holtenius and Holtenius, 2007). These variations are typically associated with milk fat concentration (Mackle et al., 1999; Karcagi et al., 2010), an observation that was also made in the present study. Nevertheless, these individual diversities in milk fat and plasma insulin concentrations, and their possible influence on milk lipid concentration and composition, have only scarcely been studied. We found that the 2 groups differed in milk fat concentration as well as milk fatty acid composition. The whole milk of the HI group showed a higher concentration of longchain fatty acids (>16 carbons: C18:1, C18:2, C18:3, and $\mathrm{C} 20: 4)$ and reduced short- and medium-chain fatty acid content ( $<16$ carbons: C10:0, C12:0, and C14:0).

The higher milk concentration of long PUFA (i.e., n-3 and n-6 fatty acids), which can only be obtained from the circulation (Bauman and Griinari, 2003; Couvreur et al., 2007), in the HI group could be explained by (1) increased absorption capacity of the mammary epithelial cells or (2) increased availability of fatty acids derived from circulating $\mathrm{Tg}$. Indeed, a positive association was found between plasma insulin concentration and circulating $\mathrm{Tg}$ in dairy cows (Schwalm and Schultz, 1976). Although we found a positive association between insulin and long-chain FA ( $>16$ carbon chain length) concentration in the milk, the opposite was recorded when insulin clamp was used to study the insulin effect on milk fat composition in dairy cows in the second week postpartum (Corl et al., 2006). This inconsistency could result from differences in lactation stage: insulin clamp performed so close to parturition 


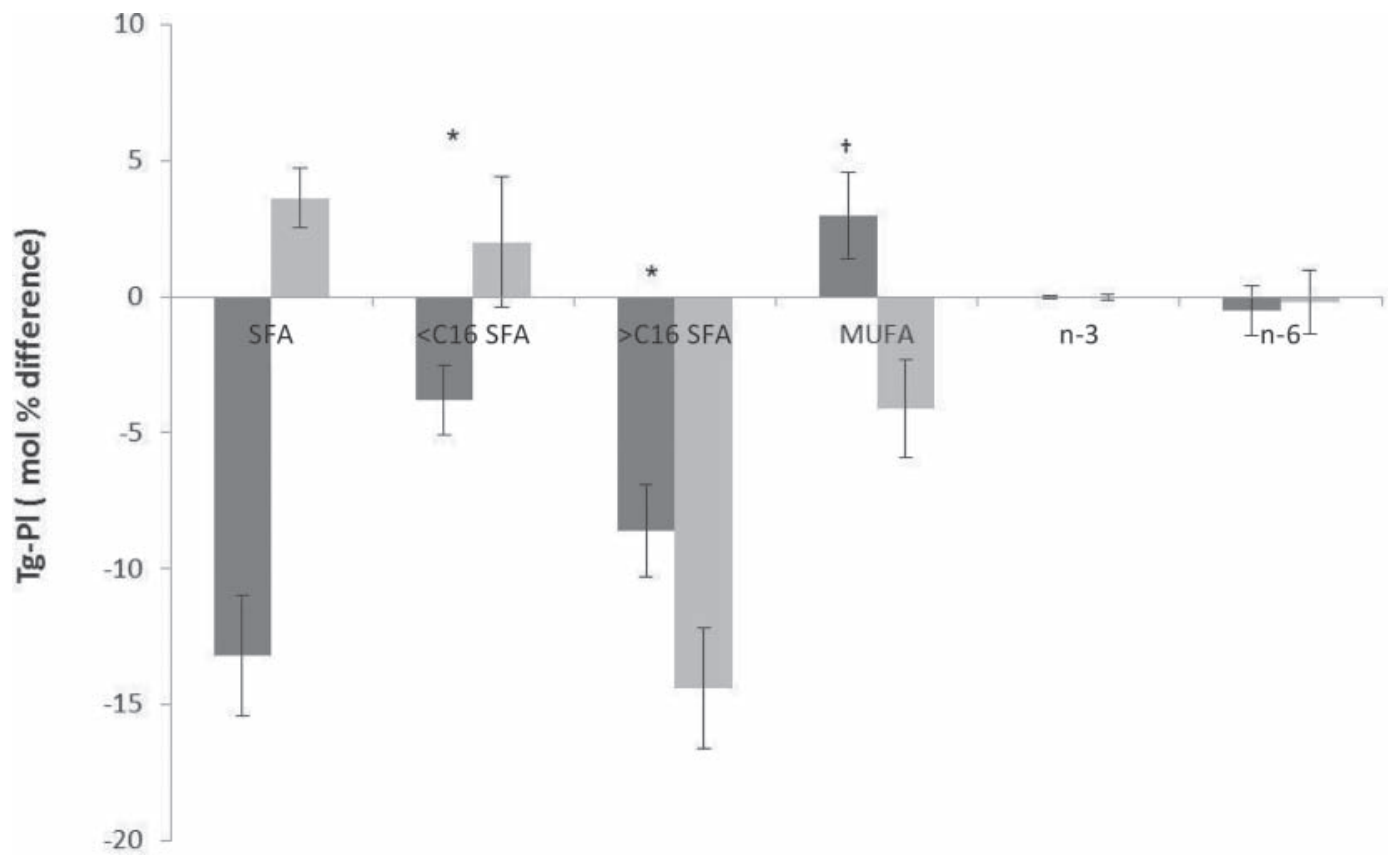

Figure 1. Relative compositional differences of FA classes between neutral (triglyceride, Tg) and polar lipid (phospholipid, Pl) based on milk FA composition in cows with high or low insulin plasma concentration (HI and LI, respectively). Values ( \pm SE) represent differences between the concentration of each FA class in the Tg fraction and phospholipid (Pl) fraction in HI (dark gray) and LI (light gray) cows. Positive values indicate a higher concentration of the FA class in the $\mathrm{Tg}$ fraction and negative values indicate a higher concentration in the $\mathrm{Pl}$ fraction. SFA $=$ mol\% sum of all SFA (including C16:0); $<\mathrm{C} 16 \mathrm{SFA}=\operatorname{mol} \%$ sum of C8:0, C10:0, C12:0, and C14:0; >C16 SFA = mol\% sum of C18:0, C20:0, $\mathrm{C} 22: 0$, and $\mathrm{C} 24: 0 ; \mathrm{MUFA}=$ mol\% sum of all MUFA; $\mathrm{n}-6=$ sum of mol\% values of $\mathrm{n}-6 \mathrm{PUFA} ; \mathrm{n}-3=$ sum of mol\% values of all $\mathrm{n}-3 \mathrm{FA}$. $\dagger P \leq$ $0.10,{ }^{*} P<0.05 ; \mathrm{n}=7$ for the HI group and 6 for the LI group.

Table 6. Fatty acid composition of the membrane (phospholipid) fraction in milk ${ }^{1}$ from cows with high (HI) and low (LI) plasma insulin concentrations

\begin{tabular}{lccc}
\hline FA (mol \%) & HI & LI & $P$-value $^{2}$ \\
\hline C10:0 & $0.89 \pm 0.32$ & $1 \pm 0.57$ & 0.67 \\
C12:0 & $1.3 \pm 0.29$ & $1 \pm 0.47$ & 0.20 \\
C13:0 & $6.08 \pm 2.8$ & $6.02 \pm 2.7$ & 0.91 \\
C14:0 & $6.6 \pm 1.2$ & $2.7 \pm 0.9$ & 0.03 \\
C14:1 & $1.38 \pm 0.29$ & $1.88 \pm 0.35$ & 0.30 \\
C15:0 & $1.39 \pm 0.19$ & $1.33 \pm 0.12$ & 0.74 \\
C15:1 & $1.03 \pm 0.1$ & $1.33 \pm 2.1$ & 0.47 \\
C16:0 & $1.03 \pm 0.1$ & $0.7 \pm 0.16$ & 0.14 \\
C16:1n-7 & $0.88 \pm 0.07$ & $0.97 \pm 0.2$ & 0.37 \\
C17:0 & $0.99 \pm 0.1$ & $0.098 \pm 0.04$ & 0.94 \\
C17:1 & $0.15 \pm 0.03$ & $23.3 \pm 2.8$ & 0.33 \\
C18:0 & $18.3 \pm 1.9$ & $14.03 \pm 2$ & 0.01 \\
C18:1n-9 trans & $7.6 \pm 1.3$ & $0.78 \pm 0.2$ & 0.04 \\
C18:1n-9 cis & $16.1 \pm 2.1$ & $3.3 \pm 1.3$ & 0.76 \\
C18:1n-7 & $1.01 \pm 0.07$ & $0.03 \pm 0.03$ & 0.38 \\
C18:2n-6 & $4.2 \pm 0.7$ & $0.14 \pm 0.08$ & 0.59 \\
C18:3n-6 & $0.1 \pm 0.08$ & $0.4 \pm 0.02$ & 0.47 \\
C18:3n-3 & $0.24 \pm 0.04$ & $0.25 \pm 0.06$ & 0.40 \\
C20:0 & $0.5 \pm 0.03$ & $0.32 \pm 0.14$ & 0.06 \\
C20:4n-6 & $0.26 \pm 0.04$ & $0.13 \pm 0.09$ & 0.80 \\
C20:5n-3 & $0.45 \pm 0.05$ & $0.2 \pm 0.08$ & 0.45 \\
C22:0 & $0.12 \pm 0.07$ & $1.12 \pm 0.08$ & 0.93 \\
C22:1 & $0.3 \pm 0.03$ & $0.08 \pm 0.08$ & 0.35 \\
C22:4n-6 & $0.96 \pm 0.14$ & $0.047 \pm 0.012$ & 0.04 \\
C22:6n-3 & $0.017 \pm 0.017$ & & 0.48 \\
Valies & $0.067 \pm 0.006$ & & 0.95 \\
\hline
\end{tabular}

${ }^{1}$ Values are means $\pm \mathrm{SE} ; \mathrm{n}=7$ for the HI group and $\mathrm{n}=6$ for the LI group.

${ }^{2}$ Significance level of difference between LI and HI. 


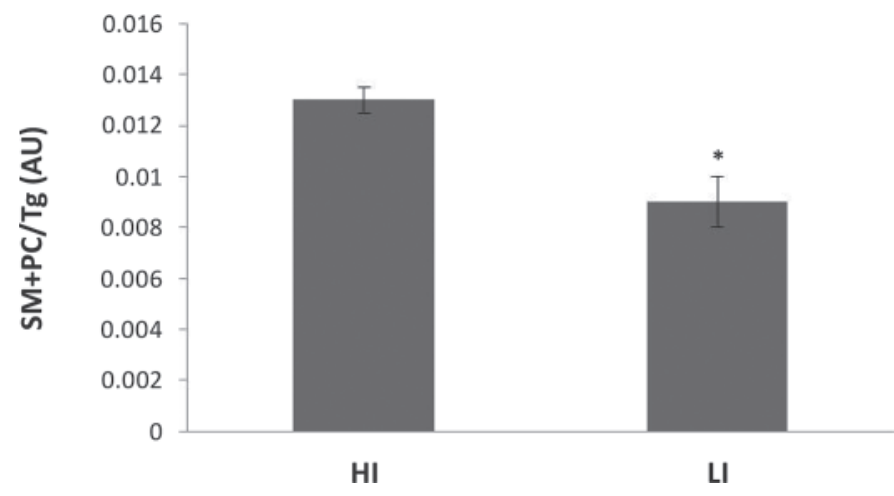

Figure 2. The ratio between polar and neutral lipids in milk from cows with high (HI) and low (LI) plasma insulin concentrations. The ratio between choline-containing phospholipids (sphingomyelin and phosphatidylcholine, $\mathrm{SM}+\mathrm{PC}$ ) and neutral lipids $(\mathrm{Tg})$ in milk was determined as the ratio between the area under the curve of the assigned peaks in each sample. AU = arbitrary units. Values are mean $\pm \mathrm{SE} ;{ }^{*} P<0.05$.

markedly reduces adipose lipolysis and the concentration of NEFA in the plasma, which serve as a major precursor for milk fat synthesis in early lactation. On the other hand, in the present study, variations in plasma insulin concentration could be assigned to physiological differences between subpopulations in the herd rather than a physiological response to clamp, diet, or energy balance.

The most interesting phenomenon observed in the present study was that the source of the FA influences their fate in the mammary gland in terms of being directed to fat or membrane synthesis. The HI group partitioned relatively more medium-chain SFA for membrane synthesis and less for fat synthesis compared with the LI group. Medium-chain fatty acids that were determined (C8 to C14) in milk are considered to be synthesized de novo. The HI group partitioned relatively more MUFA for fat synthesis, whereas more MUFA were partitioned for membrane synthesis by the LI group. Interestingly, both groups preferred longer SFA as a source for membrane synthesis. This suggests that both groups prefer preformed over de novosynthesized SFA for membrane synthesis. It should be noted that the results indicate relative compositional changes between the milk lipid fractions and not absolute values. Nonetheless, it appears that metabolic factors such as insulin might be involved in modulating fatty acid distribution between membrane and fat cell compartments.

As mentioned, the membrane material in milk (i.e., the milk fat globule membrane) consists of $\mathrm{Pl}$ that originate from the apical membrane of the secreting mammary gland epithelial cell (Mather and Keenan, 1998; Heid and Keenan, 2005). Hence, the differences in milk lipid composition found in the present study suggest compositional differences in the mammary gland epithelial cell membrane. As indicated, the HI and LI groups differed in their milk fat concentration; thus, membrane compositional modifications are also associated with the lipogenic capacity of the cells. Although the importance of cellular membrane lipid composition has been illustrated for cellular differentiation status of the mammary epithelium (Glunde et al., 2004) and insulin sensitivity of muscle cells (Pan et al., 1995; Janovská et al., 2010), membrane composition of the mammary gland cells has not been studied in relation to metabolic status of the animal or milk composition.

If, indeed, insulin affects circulating FA availability for mammary gland utilization, as well as FA partitioning between membrane and fat synthesis, then one might expect these differences to be reflected in the milk $\mathrm{Pl}$ versus $\mathrm{Tg}$ concentrations. Indeed, milk from the HI group had a higher ratio of choline-containing $\mathrm{Pl}$ to $\mathrm{Tg}$. The choline-containing $\mathrm{Pl}$ are sphingomyelin and phosphatidylcholine, which have been shown to account for more than $60 \%$ of the polar lipids in milk (Jensen and Thompson, 1995). Differences in lipid species composition of milk have been shown by us (Argov et al., 2008; Mesilati- Stahy et al., 2011) and others (Lopez et al., 2008) to be associated with the mean diameter of milk fat globules. The results presented herein imply that metabolic factors modulate fatty acid partitioning between fat and membrane compartments by the mammary gland cells, which consequently alter milk lipid composition.

\section{ACKNOWLEDGMENTS}

This research was supported by the Israeli Dairy Board grant no. 870-0261 and the Chief Scientist of the Israeli Ministry of Agriculture grant no. 820-0254.

\section{REFERENCES}

Allred, S. L., T. R. Dhiman, C. P. Brennand, R. C. Khanal, D. J. McMahon, and N. D. Luchini. 2006. Milk and cheese from cows fed calcium salts of palm and fish oil alone or in combination with soybean products. J. Dairy Sci. 89:234-248.

Argov, N., S. Wachsmann-Hogiu, S. L. Freeman, T. Huser, C. B. Lebrilla, and J. B. German. 2008. Size-dependent lipid content in human milk fat globules. J. Agric. Food Chem. 56:7446-7450.

Bachman, K. C., M. J. Hayen, D. Morse, and C. J. Wilcox. 1988. Effect of pregnancy, milk yield and somatic cell count on bovine milk fat hydrolysis. J. Dairy Sci. 71:925-931.

Bauman, D. E., and J. M. Griinari. 2003. Nutritional regulation of milk fat synthesis. Annu. Rev. Nutr. 23:203-227.

Bernal-Santos, G., A. M. O'Donnell, J. L. Vicini, G. F. Hartnell, and D. E. Bauman. 2010. Hot topic: Enhancing omega-3 fatty acids in milk fat of dairy cows by using stearidonic acid-enriched soybean oil from genetically modified soybeans. J. Dairy Sci. 93:32-37.

Burgess, J. W., T. A. Neville, and P. Rouillard. 2005. Phosphatidylinositol increases HDL-C levels in humans. J. Lipid Res. 46:350-355. 
Coffey, M. P., G. Simm, and S. Brotherstone. 2002. Energy balance profiles for the first three lactations of dairy cows estimated using random regression. J. Dairy Sci. 85:2669-2678.

Corl, B. A., S. T. Butler, W. R. Butler, and D. E. Bauman. 2006. Short communication: Regulation of milk fat yield and fatty acid composition by insulin. J. Dairy Sci. 89:4172-4175.

Couvreur, S., C. Hurtaud, P. G. Marnet, P. Faverdin, and J. L. Peyraud. 2007. Composition of milk fat from cows selected for milk fat globule size and offered either fresh pasture or a corn silage-based diet. J. Dairy Sci. 90:392-403.

de Vries, M. J., and R. F. Veerkamp. 2000. Energy balance of dairy cattle in relation to milk production variables and fertility. J. Dairy Sci. 83:62-69.

Duivenvoorden, I., P. J. Voshol, P. C. N. Rensen, W. van Duyvenvoorde, J. A. Romijn, J. J. Emeis, L. M. Havekes, and W. F. Nieuwenhuizen. 2006. Dietary sphingolipids lower plasma cholesterol and triacylglycerol and prevent liver steatosis in APOE*3 Leiden mice. Am. J. Clin. Nutr. 84:312-321.

Folch, J., M. Lees, and H. Sloane-Stanley. 1957. A simple method for the isolation and purification of total lipids from animal tissues. J. Biol. Chem. 226:497-509.

Glunde, K., C. Jie, and Z. M. Bhujwalla. 2004. Molecular causes of the aberrant choline phospholipid metabolism in breast cancer. Cancer Res. 64:4270-4276.

Gong, J. G., W. J. Lee, P. C. Garnsworthy, and R. Webb. 2002. Effect of dietary-induced increases in circulating insulin concentrations during the early postpartum period on reproductive function in dairy cows. Reproduction 123:419-427.

Griinari, J. M., M. A. McGuire, D. A. Dwyer, D. E. Bauman, and D. L. Palmquist. 1997. Role of insulin in the regulation of milk fat synthesis in dairy cows. J. Dairy Sci. 80:1076-1084.

Heid, H. W., and T. W. Keenan. 2005. Intracellular origin and secretion of milk fat globules. Eur. J. Cell Biol. 84:245-258.

Holtenius, P., and K. Holtenius. 2007. A model to estimate insulin sensitivity in dairy cows. Acta Vet. Scand. 49:29.

Janovská, A., G. Hatzinikolas, M. Mano, and G. A. Wittert. 2010. The effect of dietary fat content on phospholipid fatty acid profile is muscle fiber type dependent. Am. J. Physiol. Endocrinol. Metab. 298:E779-E786

Jensen, R. G., and M. P. Thompson. 1995. Handbook of Milk Composition. Academic Press, San Diego, CA.

Karcagi, R. G., T. Gaal, P. Ribiczey, G. Huszenicza, and F. Husveth. 2010. Milk production, peripartal liver triglyceride concentration and plasma metabolites of dairy cows fed diets supplemented with calcium soaps or hydrogenated triglycerides of palm oil. J. Dairy Res. 77:151-158.

Lissner, L., and B. L. Heitmann. 1995. Dietary fat and obesity: Evidence from epidemiology. Eur. J. Clin. Nutr. 49:79-90.

Lopez, C., V. Briard-Bion, O. Menard, F. Rousseau, P. Pradel, and J. M. Besle. 2008. Phospholipid, sphingolipid, and fatty acid compo- sitions of the milk fat globule membrane are modified by diet. J. Agric. Food Chem. 56:5226-5236.

Mackle, T. R., D. A. Dwyer, K. L. Ingvartsen, P. Y. Chouinard, J. M. Lynch, D. M. Barbano, and D. E. Bauman. 1999. Effects of insulin and amino acids on milk protein concentration and yield from dairy cows. J. Dairy Sci. 82:1512-1524.

Mather, I. H., and T. W. Keenan. 1998. Origin and secretion of milk lipids. J. Mammary Gland Biol. Neoplasia 3:259-273.

Mesilati-Stahy, R., K. Mida, and N. Argov-Argaman. 2011. Size-dependant lipid content of bovine milk fat globules and membrane phospholipids. J. Agric. Food Chem. 59:7427-7435.

Newburg, D. S. 2009. Neonatal protection by an innate immune system of human milk consisting of oligosaccharides and glycans. J. Anim. Sci. 87:26-34.

Nilsson, A., and R. D. Duan. 2006. Absorption and lipoprotein transport of sphingomyelin. J. Lipid Res. 47:154-171.

NRC. 2001. Nutrient Requirements of Dairy Cattle. 7th ed. Natl. Acad. Press, Washington, DC.

Or-Rashid, M. M., N. E. Odongo, T. C. Wright, and B. W. McBride. 2009. Fatty acid profile of bovine milk naturally enhanced with docosahexaenoic acid. J. Agric. Food Chem. 57:1366-1371.

Palmquist, D. L., C. L. Davis, R. E. Brown, and D. S. Sachan. 1969 Availability and metabolism of various substrates in ruminants. V. Entry rate into the body and incorporation into milk fat of $\mathrm{D}(-)$ ß-hydroxybutyrate. J. Dairy Sci. 52:633-638.

Pan, D. A., S. Lillioja, M. R. Milner, A. D. Kriketos, L. A. Baur, C. Bogardus, and L. H. Storlien. 1995. Skeletal muscle membrane lipid composition is related to adiposity and insulin action. J. Clin. Invest. 96:2802-2808.

Pfeuffer, M., and J. Schrezenmeir. 2007. Milk and the metabolic syndrome. Obes. Rev. 8:109-118.

Schwalm, J. W., and L. H. Schultz. 1976. Relationship of insulin concentration to blood metabolites in the dairy cow. J. Dairy Sci $59: 255-261$

Timmen, H., and S. Patton. 1988. Milk fat globule: Fatty acid composition, size and in vivo regulation of fat liquidity. Lipids 23:685689

WHO. 2000. Obesity: Preventing and managing the global epidemic. Report of a WHO consultation. World Health Org. Tech. Rep. Ser. 894:1-253.

Wildman, E. E., G. M. Jones, P. E. Wagner, R. L. Boman, H. F. Troutt Jr., and T. N. Lesch. 1982. A dairy cow body condition scoring system and its relationship to selected production characteristics. J. Dairy Sci. 65:495-501.

Yandrasitz, J. R., G. Berry, and S. Segal. 1981. High-performance liquid chromatography of phospholipids with UV detection: Optimization of separations on silica. J. Chromatogr. 225:319-328. 